\title{
Estimating Poverty Transitions in Turkey Using Repeated Cross-Sectional Data*
}

\author{
Ömer LIMANLI ${ }^{1} \odot$
}

\begin{abstract}
In order to fight poverty more effectively, it is vital to determine the extent to which households are chronic or transient poor. In this context, this paper has two aims. The first is to estimate poverty transition between 2006 and 2016 in Turkey using a newly developed synthetic panel method. With this method, the transition of poverty between two-time points can be estimated without the need for real panel data. The second aim of the study is to test how well this method works. To this end, the analysis has been performed once again by using real panel data for the years 2006-2009 and 20132016. The findings show that the percentage of households those who chronically poor is between $3.9 \%$ and $10.7 \%$, the percentage of those who escaped from poverty is between $12.1 \%$ and $20.8 \%$ and the percentage of those who fall into poverty is between $5.4 \%$ and $12.2 \%$. The analysis with actual panel data has revealed that the method works quite well.
\end{abstract}

Keywords: cross-sectional data, poverty, poverty transition, synthetic panel, Turkey.

JEL Codes: $\mathrm{C} 23, \mathrm{C} 31,132$

The first goal of the United Nation's (UN) Millenium Development Goals is to reduce the number of people who live in extreme poverty and to eliminate hunger. The results suggest that more than 1 billion people have been saved from extreme poverty. However, 800 million people still live in extreme poverty across the globe (UN, 2019). We do not know how many of those 800 million people fell into extreme poverty first time or how many of them were already in extreme poverty. To discover who moves in and out of the poverty (in the extreme form or not), data contain information about the same analysis units (individuals or households) for multiple time points are needed. Fortunately, panel structured datasets meet this feature. The problem at this point is that panel data is an exception rather than a rule for developing countries. The lack of necessary data has made analysing the poverty transition in those countries complicated for many years.

In his seminal paper, Deaton (1985) has developed the pseudo-panel data method, allowing the use of cross-sectional data when no actual panel data are available. In pseudo-panel data, individuals are classified as homogenous cohorts according to their specific characteristics. The most used character is the year of birth. So, individuals are grouped in specified age categories, and the cohort averages are used observations (Verbeek, 2008). Although Bane \& Ellwood (1986) used the actual panel in their pioneering study examining poverty from a dynamic perspective, pseudo-panel or cross-sectional data have been used extensively in the dynamic poverty analysis due to the fact that the panel data is an exception for most developing countries. For instance, Gibson (2001), Antman \& McKenzie (2007) and Cuesta, Ñopo, \& Pizzolitto (2011) have utilised repeated cross-sectional data for analysis of chronic poverty, income and earning mobility, among others. Despite the emphasised advantage, the main criticism of repeated cross-sectional data is that the use of cohorts compels the researchers to make a trade-off between the number of cohorts and the number of observations per cohort. If the number of the cohort is to be higher, which means more analysis units, the number of observations in each cohort must be reduced. This will

\footnotetext{
"The abstract of this paper has been presented at the 20th National Economic Symposium organized by the Turkish Economic Association held on 17-18 October 2019 at the Çukurova University.
}

'omerlimanli@duzce.edu.tr 
increase the within-cohort variance and damage the estimation efficiency. There is no certainty in the literature about the number of cohort and the number of observations for each cohort. Therefore, there has been a need to develop more effective analysis methods.

As is in many previous studies, balanced panel data have been employed to scrutinise the dynamics of poverty in Turkey. In all of these studies, Survey on Income and Living Conditions (SILC) panel data which conducted since 2006 by the Turkey Statistics Institute (TurkStat) has been used. For instance, Acar \& Başlevent (2014) have estimated the determinants of entry and exit from poverty for the 2007-2010 period using the traditional probit estimation method. They concluded that the employment status and education level of the household leader was strictly related to the change in the poverty situation. Similarly, Acar (2014) examined multidimensional poverty transitions for 2007-2010. Random effects probit model results show that the increase in the level of education and the homeownership reduce the probability of being multi-dimensional poor. Şeker \& Dayıoğlu (2015), unlike previous studies, have used the spell approach of Bane and Ellwood (1985) to perform a duration analysis for the period 2005-2008. They have revealed that almost a quarter of the poor are in persistent poverty. Using a similar method, Dayioğlu \& Demir Şeker (2016) have examined child poverty in the period 2006-2009 and found that 30 per cent of poor children has been poor during the whole period. Lastly, Sigeze \& Şengül (2018) have used the multinomial panel probit method to estimate the determinants of the poverty dynamics of households and chronic poverty for the 2009-2012 period. The results differ according to the characteristics of the household head and the household. Nevertheless, this study can not tell us what proportion of poor households is transient or chronically poor.

The characteristic feature of all these studies is that the time dimension in the panel data they use is at most four years. This is since SILC has a rotating panel structure. That is, one-quarter of the sample is dropped every year, and a new sample is added instead. Therefore, one-quarter of the sample can be followed for a maximum of four years. Considering the structure of the phenomenon of poverty, it can be said that four years is a short period. Poverty is a result of structural problems. ${ }^{1}$ Therefore, the solution of structural problems also requires time. To be analysed for a more extended period of poverty transition is thought to reveal more consistent results on how the poverty changes in Turkey. However, it is evident that this cannot be done with the methods employed so far and using four-year panel data.

Taking into account the studies carried out on Turkey, the aim of this paper is to estimate poverty transitions in Turkey using cross-sectional data for the period 2006-2016. To this end, the newly developed method proposed by Dang, Lanjouw, Luoto, \& McKenzie (2014) has been employed. This method allows the calculation of transient and chronic poverty rates between two-time points without the need for panel data. Several validation studies have shown that this method works reasonably well (Cruces et al., 2015; Herault \& Jenkins, 2018; Urzainqui, 2017). The primary motivation behind this study is the fact that different policy sets are needed to reduce transient and chronic poverty. Transient poverty is a short time for individuals or households to remain poor and is caused by shocks such as diseases, natural disasters or death. Chronic poverty is the result of structural problems such as income distribution disorder, constraints on access to education, inequality of opportunity, or inter-regional differences in development. Therefore, it is believed that the present paper will help policymakers to develop more effective policies in terms of poverty alleviation. Moreover, it is also aimed to demonstrate how well the method works by using actual panel data.

This paper proceeds as follows. The method proposed by Dang et al. (2014) is explained in detail in Section 1. First, the background of the methodological approach is explained briefly, and then the calculation approach is presented step by step. Section 2 provides detailed information on the data set and variables used in the study. The empirical findings and robustness exercise are provided in Section 3. The article concludes with a brief discussion in Section 4.

\section{Method}

This section is mostly based on Dang et al. (2014) and Bierbaum \& Gassmann (2012). The logic behind the method of Dang et al. (2014) can be explained as follows. Suppose we have cross-section data collected at two-time points. Let time points are represented by 1 and 2 . Since these are cross-sectional data, the units in both dataset are different. Therefore, the income or consumption of the households observed in round 1

${ }^{1}$ For a discussion of poverty from political economy perspective, see Bahçe \& Köse (2017). See also Buğra \& Keyder (2005) for the social policy, and Wuripe (2018) for literature examination in tersm of government role in poverty eradication. 
cannot be known in round 2, or vice versa. One thing to do at this point is to estimate the value of household income or consumption in the second round observed in the first round. This estimation can be carried out by applying the ordinary least squares (OLS) method to the consumption or income equation using the time-invariant household variables observed in both rounds.

To put it more formally, let $y_{i t}$ be the per capita income or consumption in the household $i$ and the round $t, t=1,2$. Likewise, $x_{i t}$ is the vector contains time-invariant household characteristics like sex, language, religion or birth of region and $\varepsilon_{i t}$ is the error term. So, the estimation equation that can be used for both rounds can be written as follows,

$$
y_{i t}=\beta_{t}^{\prime} x_{i t}+\varepsilon_{i t}
$$

However, it is not possible to estimate the change in the poverty status of households directly by using repeated cross-sectional data. In other words, we cannot predict the following joint possibilities; $\operatorname{Pr}\left(y_{i 1}<z_{1}\right.$ and $\left.y_{i 2}>z_{2}\right)$ : poor-nonpoor, $\operatorname{Pr}\left(y_{i 1}<z_{1}\right.$ and $\left.y_{i 2}<z_{2}\right)$ : poor-poor, $\operatorname{Pr}\left(y_{i 1}>z_{1}\right.$ and $\left.y_{i 2}<z_{2}\right)$ : nonpoor-poor and $\operatorname{Pr}\left(y_{i 1}>z_{1}\right.$ and $\left.y_{i 2}>z_{2}\right)$ :nonpoor-nonpoor, where $z_{t}$ is the poverty line in the corresponding round. Instead, by using the coefficients obtained from the estimation of the first-period equation and the time-invariant household characteristics of the second period, the estimates for the first period of the households in the second period can be obtained. Dang et al. (2014) refer to the data obtained in this way as "synthetic panel".
Two assumptions are necessary for the method to function (Dang et al., 2014: 114). According to the first assumption, the population where the sample is collected should not change between two rounds. The reason why this assumption is required is that the household characteristics remain the same over time as a result of the sampling population does not change so that the first round can be estimated by using the data obtained from the second round. The second assumption requires that the correlation between the error terms obtained from the two rounds is not negative. Dang et al. (2014) justify this assumption as follows. Because of the fixed household characteristics in the error terms, households with high (low) income or consumption in the first round will also have high (low) income or consumption in the second round.

Furthermore, a positive autocorrelation will be observed in the error term due to the external shocks affecting household income or consumption. Also, the authors have not entirely ignored the possibility of a negative correlation. For example, households with limited access to credit will reduce their current expenditures for future payments. This will cause the error term to be negatively correlated. Lastly, a zero or one correlation means that the poverty status of all households in the first round has changed in the second round (upper bound) and that no household's poverty status has changed (lower bound), respectively. Under the assumptions mentioned above, the upper and lower bound of poverty mobility, which Dang et al. (2014) call the "nonparametric bounds" can be estimated by the following steps.

To estimate nonparametric upper bound;

Step 1: Estimate the equation 1 with OLS using data from round 1, obtain $\hat{\beta}_{1}^{\prime}$ and $\hat{\varepsilon}_{i 1}$.

Step 2: For each household in the second round, select randomly a residual with replacement from the residuals calculated in the first step. Denote these residuals with $\hat{\varepsilon}_{i 1}^{2}$. Using data from round $2, \hat{\beta}_{1}^{\prime}$ and $\hat{\varepsilon}_{i 1}^{2}$, estimate the income level of the households in the first round: $\hat{y}_{i 1}^{2 U}=\hat{\beta}_{1}^{\prime} x_{i 2}+\hat{\varepsilon}_{i 1}^{2}$.

Step 3: Calculate the following probabilities using $\hat{y}_{i 1}^{2 U}$ and parameters estimated in the previous steps.

$$
\begin{aligned}
& P\left(y_{i 1}^{2 U}<z_{1} \text { and } y_{i 2}>z_{2}\right), P\left(y_{i 1}^{2 U}>z_{1} \text { and } y_{i 2}<z_{2}\right), \\
& P\left(y_{i 1}^{2 U}>z_{1} \text { and } y_{i 2}>z_{2}\right) \text { and } P\left(y_{i 1}^{2 U}<z_{1} \text { and } y_{i 2}<z_{2}\right) .
\end{aligned}
$$

Step 4: Repeat step 2 and step $3 \mathrm{R}$ times and take the average of each calculation. 
To estimate nonparametric lower bound:

Step 1: Estimate the equation 1 with OLS using data from round 1, obtain $\hat{\beta}_{1}^{\prime}$ and the standard error of the $\varepsilon_{i 1}, \hat{\sigma}_{\varepsilon_{1}}$ Similarly, obtain the $\hat{\beta}_{2}$ and $\hat{\sigma}_{\varepsilon_{2}}$ using round 2 data, moreover, calculate $\gamma=\frac{\hat{\sigma}_{\varepsilon_{1}}}{\hat{\sigma}_{\varepsilon_{2}}}$.

Step 2: Using data from round 2, $\hat{\beta}_{1}^{\prime}$ and $\hat{\varepsilon}_{i 2}$, estimate the income level of the households in the first round for the household in the second round: $\hat{y}_{i 1}^{2 L}=\hat{\beta}_{1}^{\prime} x_{i 2}+\gamma \hat{\varepsilon}_{i 2}$.

Step 3:

Calculate the following probabilities using $\hat{y}_{i 1}^{2 L}$ and parameters estimated in the previous steps.

$$
\begin{aligned}
& P\left(y_{i 1}^{2 L}<z_{1} \text { and } y_{i 2}>z_{2}\right), P\left(y_{i 1}^{2 L}>z_{1} \text { and } y_{i 2}<z_{2}\right), \\
& P\left(y_{i 1}^{2 L}>z_{1} \text { and } y_{i 2}>z_{2}\right) \text {, and } P\left(y_{i 1}^{2 L}<z_{1} \text { and } y_{i 2}<z_{2}\right) .
\end{aligned}
$$

In the nonparametric estimation method, the bounds of poverty mobility are estimated using the smallest (0) and the highest (1) value of the correlation coefficient. As expected, the correlation coefficient generally takes a value between 0 and 1. A parametric approach can be used to narrow the range of values the correlation coefficient can take. This approach requires a more strict version of the second assumption expressed earlier. According to this assumption, with the non-negative correlation coefficient $\rho$, and standard deviations $\sigma_{\varepsilon_{1}}$ and $\sigma_{\varepsilon_{2}}, \varepsilon_{1}$ and $\varepsilon_{2}$ follows the bivariate normal distribution. In the parametric analysis, it is assumed that the correlation coefficient has a maximum and minimum value between zero and one, $\rho \in\left[\rho_{s}, \rho_{h}\right], 0<\rho_{s}<\rho_{h}<1$, where $\rho_{s}$ and $\rho_{h}$ are the smallest and the highest hypothesised values of the $\rho$, respectively. Dang et al. (2014) have used the actual panel data of four developing countries besides Indonesia and Vietnam to calculate the correlation values between the residuals (Table 2). Based on the correlation coefficients obtained from these estimates, authors have chosen the $0.2-0.8$, and $0.3-0.7$ pairs in the bound estimates.

Consequently, to estimate parametric upper bound;

Step 1: $\quad$ Estimate the equation 1 with OLS using data from round 1 and round 2,

Step 2: obtain $\hat{\beta}_{1}^{\prime}, \hat{\beta}_{2}^{\prime}, \hat{\sigma}_{\varepsilon_{1}}$ and $\hat{\sigma}_{\varepsilon_{2}}$.

Calculate the following quantities using $\rho_{s}$.

$$
\begin{aligned}
& \hat{P}^{2 U}\left(y_{i 1}<z_{1} \text { and } y_{i 2}>z_{2}\right)=\Phi_{2}\left(\frac{z_{1}-\hat{\beta}_{1}^{\prime} x_{i 2}}{\hat{\sigma}_{\varepsilon_{1}}},-\frac{z_{2}-\hat{\beta}_{2}^{\prime} x_{i 2}}{\hat{\sigma}_{\varepsilon_{2}}},-\rho_{s}\right), \\
& \hat{P}^{2 U}\left(y_{i 1}>z_{1} \text { and } y_{i 2}<z_{2}\right)=\Phi_{2}\left(-\frac{z_{1}-\hat{\beta}_{1}^{\prime} x_{i 2}}{\hat{\sigma}_{\varepsilon_{1}}}, \frac{z_{2}-\hat{\beta}_{2}^{\prime} x_{i 2}}{\hat{\sigma}_{\varepsilon_{2}}},-\rho_{s}\right), \\
& \hat{P}^{2 U}\left(y_{i 1}>z_{1} \text { and } y_{i 2}>z_{2}\right)=\Phi_{2}\left(-\frac{z_{1}-\hat{\beta}_{1}^{\prime} x_{i 2}}{\hat{\sigma}_{\varepsilon_{1}}},-\frac{z_{2}-\hat{\beta}_{2}^{\prime} x_{i 2}}{\hat{\sigma}_{\varepsilon_{2}}}, \rho_{s}\right), \text { and } \\
& \hat{P}^{2 U}\left(y_{i 1}<z_{1} \text { and } y_{i 2}<z_{2}\right)=\Phi_{2}\left(\frac{z_{1}-\hat{\beta}_{1}^{\prime} x_{i 2}}{\hat{\sigma}_{\varepsilon_{1}}}, \frac{z_{2}-\hat{\beta}_{2}^{\prime} x_{i 2}}{\hat{\sigma}_{\varepsilon_{2}}}, \rho_{s}\right) .
\end{aligned}
$$

To estimate the parametric lower bound, replace $\rho_{s}$ with $\rho_{h}{ }^{2}$

${ }^{2}$ We would like to thank McKenzie (2019) for making the simulation code we used in the analysis publicly available. 


\section{Data}

The data used in the analysis come from Survey on Income and Living Conditions (SILC) conducted and released by the Turkish Statistical Institute (TurkStat) since 2006. SILC has rich information regarding demographic and socioeconomic characteristics of households and individuals such as sex, age, working status, health status and household conditions. The most crucial feature of SILC is its rotating panel data structure. One-quarter of the sample is replaced with a new one every year. As a result of that feature, the time dimension of the panel data is limited to four years. The data in SILC represents the information about the previous year. For example, the file for 2016 contains information for 2015. During the analysis, this fact must be kept in mind when interpreting. 2006 and 2016 are selected for analysis because the first and the last date SILC were released are 2006 and 2016. Besides, as mentioned earlier, two-panel data covering the years 2006-2009 and 2013-2016 have been utilised to test the performance of the method. The sample sizes are 10,920 and 21,870 for 2006 and 2016, respectively. Due to the difference between sample sizes, 10,920 observations have been randomly selected from 2016.

\subsection{Variables}

Equivalent disposable household income has been used as an indicator of household welfare and dependent variable in the estimations. This indicator is obtained by dividing disposable household income by the square root of the total household size. Let this indicator is denoted by $y$ as is in Equation 1. In order to identify poor households, $60 \%$ of the median income is defined as the poverty line $(z)$. Therefore, if $y<z$ the household will be considered poor. In order to give an overview of the poverty in Turkey between 2006 and 2016, results from the poverty index proposed by Foster, Greer, \& Thorbecke (1984) are given in Graph 1. It is evident that the poverty rate has fallen considerably.

While Graph 1 depicts that poverty has declined, it cannot say what percentage of households have fallen into or escaped from poverty between two years. To explore poverty mobility, twelve independent variables have been used in the estimations. In the selection process of the independent variables, both strict adherence to literature and data set constraints have been taken into consideration. Independent variables can be grouped into two categories: (i) those belonging to the household leader, and (ii) those belonging to the housing conditions. In the first category, there are five variables associated with household leaders: age, sex, education, occupation and marital status. The second category consists of seven variables: the region, household size, the number of children under five, and the presence of television, refrigerator, piping system and an indoor toilet. Detailed information about the independent variables is given in Table 1.
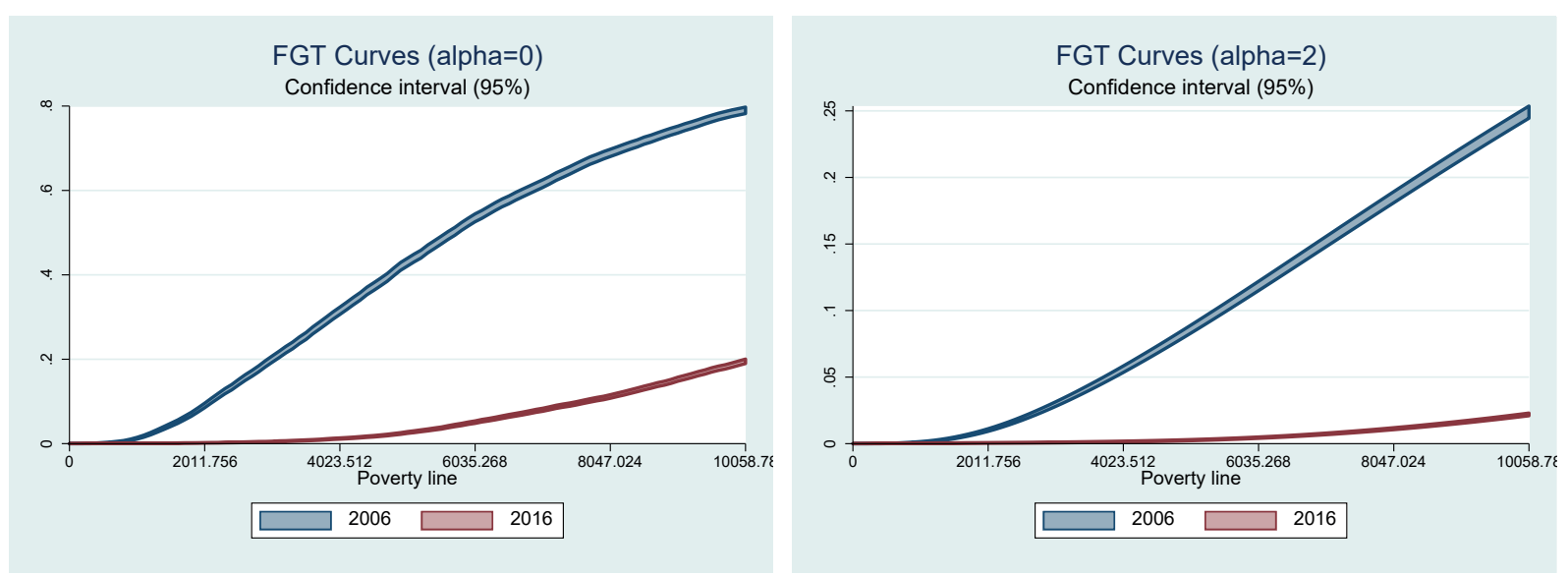

Graph 1: Poverty Rates in Turkey, 2006-2016.

Source: Own elaboration using SILC.

Notes: (i) All sample used. (ii) The highest value on the axis of poverty line represents the poverty line for 2016 . This value has also been used for 2006. The poverty line for 2006 is 3,425.05 TL. (iii) When $\alpha=0$ FGT equals to the head-cont ratio. If $\alpha>1$, the index assigns more weight to the poorest. 
Table 1: Independent Variables Used in the Analysis

\begin{tabular}{lll}
\hline Name & Variable Type & \multicolumn{1}{c}{ Variables Associated with Household Head } \\
\hline Age & $\begin{array}{l}\text { Ordered (2006) } \\
\text { Continuous (2016) }\end{array}$ & The age of household head is restricted to 25+. \\
\hline Sex & Dummy & 1 if the head is female. \\
\hline Education & Ordered & $\begin{array}{l}\text { The last completed education level of the household head. } \\
\text { Recoded as the dummy variable. Illiterate is the base category. }\end{array}$ \\
\hline Occupation & Multinomial & $\begin{array}{l}\text { Occupational category according to the ISCO-88 for 2006, and } \\
\text { ISCO-08 for 2016. Recoded as the dummy variable. Currently not } \\
\text { working is the base category. }\end{array}$ \\
\hline Marital Status & Multinomial & Recoded as the dummy variable. Grass widow is the base category. \\
\hline Region & \multicolumn{1}{c}{ Variables Associated with Household Conditions } \\
\hline Household Size & Multinomial & $\begin{array}{l}\text { Where household is interviewed. Recoded as the dummy variable. } \\
\text { Istanbul is the base category. }\end{array}$ \\
\hline The \# of children under five & Count & - \\
\hline TV & Dummy & - \\
\hline Refrigerator & Dummy & $=1$ if the household does not have coloured TV for any reason. \\
\hline Piping System & Dummy & $=1$ if the household does not have a piping system. \\
\hline Indoor Toilet & Dummy & $=1$ if the household does not have an indoor toilet.
\end{tabular}

Source: Own elaboration.

Following Dang et al. (2014), in the nonparametric analysis, not all independent variables have been used at once. Modelling has been expanded by adding independent variables step by step to the previous model. Thus, it can be seen how the prediction intervals change as the model expands. To this end, four models have been created. Related models and the variables used in each model are given below.

Model 1c: $y=f$ (age, sex, education, occupation, marital status)

Model 2c: $y=f$ (model1, region)

Model 3c: $y=f$ (model2, household size, household size ${ }^{2}$, the \# of children under five)

Model 4c: $y=f$ (model3, $t v$, refrigerator, piping system, indoor toilet)

Also, as stated earlier, real panel data has been used to test how well the method works. However, of the independent variables discussed above, the panel data set do not contain information about the region. Therefore, models using panel data are constructed as follows;

Model $1 p: y=f(a g e$, sex, education, occupation, marital status)

Model 2p: $y=f$ (model1, household size, household size ${ }^{2}$, the \# of children under five)

Model $3 p: y=f$ (model2, $t v$, refrigerator, piping system, indoor toilet)
Lastly, to compare non-parametric and parametric estimation results, only Model $1 c$ and Model $1 p$ have been estimated when using cross-sectional data and panel data, respectively. In addition, the parametric method has been once again performed using different correlation coefficients, and in case the normality assumption has been violated.

\section{Findings}

Table 2 presents the non-parametric lower and upper bound estimates of poverty transitions. Since the real panel data covering 2006 and 2016 are not available, it is not known whether the lower and upper bounds are around the actual values. Therefore, it should be noted that the upper and lower bounds in the table are estimations. The first thing that stands out in the table is that the gap between upper and lower bounds narrows as the model moves simple specification (Model1c) to final specification (Model4c). We will focus on Model4c. The ratio of chronically poor households lays between $10.7 \%$ and $3.9 \%$. The fact that the lower and upper bounds of the households that escape from poverty (P-NP) are higher than the bounds of households falling into poverty (NP-P) might be a sign of poverty reduction. This finding confirms Graph 1. 
Table 2: Poverty Transitions Using Cross-Sectional Data Between 2006 and 2016.

\begin{tabular}{|c|c|c|c|c|c|c|c|c|}
\hline \multirow[b]{2}{*}{ Poverty Status } & \multicolumn{4}{|c|}{ Nonparametric Lower Bounds } & \multicolumn{4}{|c|}{ Nonparametric Upper Bounds } \\
\hline & Model1c & Model2c & Model3c & Model4c & Model4c & Model3c & Model2c & Model1c \\
\hline P-P & 11.7 & 11.7 & 11.2 & 10.7 & 3.9 & 3.9 & 3.9 & 3.8 \\
\hline P-NP & 10.9 & 11.9 & 12 & 12.1 & 20.8 & 20.8 & 20.7 & 20.9 \\
\hline NP-P & 4.3 & 4.8 & 4.8 & 5.4 & 12.2 & 12.2 & 12.1 & 12.2 \\
\hline NP-NP & 73.1 & 72.1 & 72 & 71.8 & 63.2 & 63.2 & 63.3 & 63.1 \\
\hline$\rho$ & -.002 & .006 & .004 & .002 & & & & \\
\hline
\end{tabular}

Source: Author's calculations using SILC.

Notes: (i) Dependent variable is log(y). (ii) The number of replication is 500. (iii) P-P: Poor-Poor; P-NP: Poor-Nonpoor; NP-P: Nonpoor-Poor; NP-NP: Nonpoor-Nonpoor.

As may be recalled, the values given in Table 2 are obtained as a result of highly conservative assumptions. One of these is that the correlation coefficient only takes extreme values. The nonparametric lower and upper bound estimates are given in Table 2 are calculated under this assumption; the correlation between the error terms between the two rounds is zero or one. To relax this assumption, we have reestimated the Model1c using $\rho=(.2, .8)$ and $\rho=(.3, .7)$ pairs by parametric approach. The results of the parametric approach are given in Table 3. The findings in the first and last columns in the table are equivalent to the non-parametric estimation results. Given the $\rho$ values in Table 2, it is not surprising that the findings in these columns are close to the parametric results because the correlation is very close to zero.

\subsection{Robustness Check}

We now return to the findings using panel data in the analysis to test how well the method works. The panel data have been constructed as follows. The samples belong to 2006 and 2009 have been first pooled. The final sample was then randomly divided into two parts. The first and second sub-samples represent round 1 and round 2 , respectively. Thus, real and synthetic panels derived from the actual panel have become comparable. We will start with the results of the poverty transition between 2006 and 2009. The relevant findings are given in Table 4. The first remarkable point in the table is that the lower and upper bounds of different models are very close to each other. This is, in a way, a result of the independent variables used to remain constant, at least to a large extent, over time. We again will focus on the most extended model; Model3p. In the column named true, the table shows that $8.5 \%$ of the population was chronic poor, $78.2 \%$ did not fall into poverty at all, and $13.4 \%$ was transient poor between 2006 and 2009. Note that all values fall between the upper and lower bounds. This is a sign the method works well. Parametric estimation results also confirm that inference. All simulated values lay between lower and upper bounds. As the range of the correlation coefficient narrows, the gap between the estimated upper and lower bounds closes.

Table 3: Poverty Transitions Using Cross-Sectional Data Between 2006 and 2016

\begin{tabular}{|c|c|c|c|c|c|c|}
\hline \multirow[b]{3}{*}{ Poverty Status } & \multirow{2}{*}{\multicolumn{3}{|c|}{ Parametric Lower Bounds }} & \multirow{2}{*}{\multicolumn{3}{|c|}{ Parametric Upper Bounds }} \\
\hline & & & & & & \\
\hline & $\rho=1$ & $\rho=.8$ & $\rho=.7$ & $\rho=.3$ & $\rho=.2$ & $\rho=0$ \\
\hline P-P & 13.4 & 10.8 & 9.7 & 6.5 & 5.9 & 4.7 \\
\hline P-NP & 10.4 & 13 & 14 & 17.2 & 17.8 & 19.1 \\
\hline NP-P & 4.7 & 7.3 & 8.4 & 11.6 & 12.2 & 13.4 \\
\hline NP-NP & 71.5 & 68.9 & 67.9 & 64.7 & 64.1 & 62.8 \\
\hline
\end{tabular}

Source: Author's calculations using SILC.

Notes: (i) Dependent variable is log(y). (ii) The number of replication is 500. (iii) P-P: Poor-Poor; P-NP: Poor Nonpoor; NP-P: Nonpoor-Poor; NP-NP: Nonpoor-Nonpoor. (iv) The estimated model is Model1c in Table 2. 
The findings calculated utilised panel data covering 2013 and 2016 using the nonparametric and parametric approach are presented in Table 6 and Table 7, respectively. It is worth to compare Table 4 and Table 6 . First of all, chronic poverty has declined slightly. However, transient poverty changed considerably. Compared to the 2006-2009 period, the proportion of those who fell into poverty in 2013-2016 exceeded the rate of those who escaped from poverty. Also, the proportion of the household, which are persistently nonpoor, decreased as well.
Since we do not know about poverty transitions calculated using actual panel data between these two periods, we cannot say that stated changes increase or decrease poverty. Nevertheless, the poverty rates calculated by TurkStat using SILC decreased between the relevant periods. However, note that TurkStat uses equivalent individual disposable income. The present paper uses equivalent disposable household income. There are significant differences between these two income measures in terms of some income sources. For example, household cash and in-kind benefits, rent or security income are included in household income and not in individual income.

Table 4: Poverty Transitions Using Panel Data Between 2006 and 2009

\begin{tabular}{lrrrrrrrr}
\hline & \multicolumn{3}{c}{ Nonparametric Lower Bounds } & & \multicolumn{3}{c}{ Nonparametric Upper Bounds } \\
\cline { 2 - 4 } Poverty Status & Model1 $p$ & Model2 $p$ & Model3p & & & Model3p & Model2p & Model1 $p$ \\
\hline P-P & 15.1 & 15 & 15.1 & 8.5 & 5.9 & 5.9 & 5.6 \\
P-NP & 4.9 & 4.8 & 4.6 & 7.7 & & 14.8 & 16.4 & 16.7 \\
NP-P & .6 & .5 & .7 & 5.7 & 9.2 & 9.2 & 9.6 \\
NP-NP & 79.4 & 79.7 & 79.7 & 78.2 & & 70 & 68.4 & 68.1 \\
\hline$\rho$ & .612 & .601 & .572 & & &
\end{tabular}

Source: Author's calculations using SILC.

Notes: (i) Dependent variable is log(y). (ii) The number of replication is 500. (iii) P-P: Poor-Poor; P-NP: Poor Nonpoor; NP-P: Nonpoor-Poor; NP-NP: Nonpoor-Nonpoor.

Table 5: Poverty Transition Using Panel Data Between 2006 and 2009.

\begin{tabular}{lrrrrrrrrr}
\hline & \multicolumn{3}{c}{ Parametric Lower Bounds } & & \multicolumn{3}{c}{ Parametric Upper Bounds } \\
\cline { 2 - 3 } Poverty Status & $\rho=1$ & $\rho=.8$ & $\rho=.7$ & & True & & $\rho=.3$ & $\rho=.2$ & $\rho=0$ \\
\hline P-P & 16.6 & 12.3 & 11.1 & 8.9 & & 7.6 & 6.8 & 5.5 \\
P-NP & 1.5 & 5.8 & 7 & 9.2 & & 10.6 & 11.3 & 12.6 \\
NP-P & 1.3 & 5.5 & 6.7 & 8.8 & & 10.3 & 11 & 12.3 \\
NP-NP & 84.4 & 80.6 & 76.3 & 75.1 & & 73 & 71.5 & 70.8 \\
\hline
\end{tabular}

Source: Author's calculations using SILC.

Notes: (i) Dependent variable is log(y). (ii) The number of replication is 500. (iii) P-P: Poor-Poor; P-NP: Poor Nonpoor; NP-P: Nonpoor-Poor; NP-NP: Nonpoor-Nonpoor. (iv) The estimated model is Model $1 p$ in Table 4.

Table 6: Poverty Transitions Using Panel Data Between 2013 and 2016.

\begin{tabular}{|c|c|c|c|c|c|c|c|}
\hline \multirow[b]{2}{*}{ Poverty Status } & \multicolumn{3}{|c|}{ Nonparametric Lower Bounds } & \multirow{2}{*}{ True } & \multicolumn{3}{|c|}{ Nonparametric Upper Bounds } \\
\hline & Model1p & Model2p & Model3p & & Model3p & Model $2 p$ & Model1p \\
\hline P-P & 14.2 & 14.3 & 14 & 8.4 & 4.9 & 4.6 & 4.4 \\
\hline P-NP & .1 & .1 & .4 & 6.2 & 10.6 & 11.1 & 11.3 \\
\hline NP-P & 4.1 & 4 & 4.3 & 8.6 & 13.8 & 14.1 & 14.3 \\
\hline NP-NP & 81.7 & 81.6 & 81.3 & 76.7 & 70.7 & 70.2 & 70 \\
\hline$\rho$ & .609 & .593 & .586 & & & & \\
\hline
\end{tabular}

Source: Author's calculations using SILC.

Notes: (i) Dependent variable is log(y). (ii) The number of replication is 500. (iii) P-P: Poor-Poor; P-NP: Poor Nonpoor; NP-P: Nonpoor-Poor; NP-NP: Nonpoor-Nonpoor. 
Table 7: Poverty Transitions Using Panel Data Between 2013 and 2016.

\begin{tabular}{lrrrrrrrrr}
\hline & \multicolumn{3}{c}{ Parametric Lower Bounds } & & \multicolumn{3}{c}{ Parametric Upper Bounds } \\
\cline { 2 - 3 } Poverty Status & $\rho=1$ & $\rho=.8$ & $\rho=.7$ & & & $\rho=.3$ & $\rho=.2$ & $\rho=0$ \\
\hline P-P & 15.8 & 11.8 & 10.6 & 9.2 & & 6.9 & 6.2 & 4.8 \\
P-NP & 0 & 4 & 5.2 & 6.3 & & 8.9 & 9.6 & 11 \\
NP-P & 4.1 & 8.1 & 9.3 & 10.4 & & 13 & 13.8 & 15.1 \\
NP-NP & 82.9 & 80.1 & 76.1 & 74.9 & & 74.1 & 70.4 & 69.1 \\
\hline
\end{tabular}

Source: Author's calculations using SILC.

Notes: (i) Dependent variable is log(y). (ii) The number of replication is 500. (iii) P-P: Poor-Poor; P-NP: Poor Nonpoor; NP-P: Nonpoor-Poor; NP-NP: Nonpoor-Nonpoor. . (iv) The estimated model is Model1 p in Table 6.

Finally, the lower and upper bound estimates for the different correlation values using the actual panel for the 2013-2016 period are presented in Table 7. When switching from specification one, where $\rho$ is equal to 0 and 1 , to specification two, where $\rho$ is equal to 2 and .8 , the upper and lower bounds vary dramatically. The last specification has once again reached the narrowest upper and lower bounds. According to the last specification, true poverty mobility rates are much closer to the lower bound. Considering the $\rho$ value at the bottom of the first column in Table 6, this is not a coincidence. This fact reveals once again that the model works reasonably well.

\section{Conclusion and Discussion}

The major problem experienced in poverty studies on underdeveloped or developing countries is that these countries do not have balanced panel data covering an extended period. This constraint causes poverty mobility to be calculated for short periods. However, due to the nature of poverty, long-term periods are needed to see the effects of policies aimed at preventing poverty. The recently developed synthetic panel method has made it possible to analyse poverty transitions without the need for long-term panels. Unlike previous studies employed traditional methods and analysed narrower period, this paper has tried to estimate the lower and upper bounds of poverty mobility in Turkey using this newly developed method. It is also tested how well the method works.

The findings from the nonparametric approach using purely cross-sectional data indicate that the proportion of chronically poor people is on somewhere between $3.9 \%$ and $10.7 \%$ for the most extended model. Compared to findings from Latin America or the African, this ratio is quite good. For example, Cruces et al. (2015, p. 170-171) have estimated that the lower and upper bounds for chronic poverty is $28.83 \%-18.28 \%$ in Peru for the period 2008-2009, and 37.74\%-31.09\% in Nicaragua for the period 2001-2005. Dang \& Dabalen (2018, p. 13 ) suggests that $35.9 \%$ of the sample is chronically poor using 21 countries from Africa. Our estimates obtained from actual panels covering 2006-2009 and 2013-2016 periods demonstrate that chronic poverty rate almost remained the same around $8.4 \%$. The good news is that the proportion of those who have escaped from poverty is significantly higher than that of those falling into poverty. Estimates demostrate that the proportion of those who fall into poverty is between $5.4 \%$ and $12.2 \%$, while the proportion of those who escape from poverty is between $12.2 \%$ and $20.8 \%$. Moreover, Turkey has also given a good test on the eradication of extreme poverty. According to the Millennium Development Goals' first article, it was aimed to eradicate extreme poverty in 2015. Turkey has not altogether eliminated extreme poverty, though, has managed to reduce significantly. The ratio of people living in extreme poverty in 2017 was $0.1 \%$ while it was $3 \%$ in 1994 (World Bank, 2021). Turkey may consider lowering or completely removing income taxes levied on the minimum wage, which is the sole income source for many poor households if it wants to reduce this ratio further. The Parametric approach also suggests suitable true values fall into between bounds.

Despite its original aspects, this study has some limitations. First of all, there is no region information on the questionnaire of the panel data. In countries where there is a significant development gap between regions, such as Turkey, to examine the poverty ignoring the region factor will undermine poverty estimates. It is believed that the estimates to be made in the presence of the region variable will be more accurate than the current estimates. Second, the analysis was not carried out at the sub-sample level. The reason for this is that the sub-samples are quite small in some of the essential variables associated with household leader 
or household conditions. We believe that better predictions will be made in the future with the richer data set and larger samples. Lastly, developing models to consider endogeneity will improve prediction accuracy. The complexity of the model makes it difficult for now. 


\section{References}

Acar, A. (2014). The Dynamics of Multidimensional Poverty in Turkey (BETAM Working Paper Series No. 14). Retrieved from https://betam.bahcesehir.edu.tr/2014/10/the-dynamics-of-multidimensional-poverty-in-turkey/

Acar, A., \& Baslevent, C. (2014). Examination of the Transitions of Households into and out of Poverty in Turkey (BETAM Working Paper Series No. 15). Retrieved from https://betam. bahcesehir.edu.tr/2014/11/examination-of-the-transitions-of-households-into-and-out-of-poverty-in-turkey/

Antman, F., \& McKenzie, D. J. (2007). Earnings Mobility and Measurement Error: A Pseudo-Panel Approach. Economic Development and Cultural Change, 56(1), 125-161. https:// doi.org/10.1086/520561

Bahce, S., \& Kose, A. H. (2017). Social Classes and the Neo-Liberal Poverty Regime in Turkey, 2002-2011. Journal of Contemporary Asia, 47(4), 575-595. https://doi.org/10.10 80/00472336.2017.1325919

Bane, M. J., \& Ellwood, D. T. (1986). Slipping into and out of Poverty: The Dynamics of Spells. The Journal of Human Resources, 21(1), 1-23. https://doi.org/10.2307/145955

Bierbaum, M., \& Gassmann, F. (2012). Chronic and Transitory Poverty in the Kyrgyz Republic: What Can Synthetic Panels Tell Us? (UNU-MERIT Working Paper Series No. 64). Retrieved from http://collections.unu.edu/eserv/UNU:425/ wp2012-064.pdf

Bugra, A., \& Keyder, C. (2005). Poverty and Social Policy in Contemporary Turkey. Retrieved from https://pdfs. semanticscholar.org/0eaf/37807c570d98e1002831f265f8316c774769.pdf

Cruces, G., Lanjouw, P., Lucchetti, L., Perova, E., Vakis, R., \& Viollaz, M. (2015). Estimating poverty transitions using repeated cross-sections: a three-country validation exercise. The Journal of Economic Inequality, 13(2), 161-179. https:// doi.org/10.1007/s10888-014-9284-9

Cuesta, J., Ñopo, H., \& Pizzolitto, G. (2011). Using pseudo-panels to measure income mobility in Latin America. Review of Income and Wealth, 57(2), 224-246. https://doi. org/10.1111/j.1475-4991.2011.00444.x

Dang, H.-A. H., \& Dabalen, A. L. (2018). Is Poverty in Africa Mostly Chronic or Transient? Evidence from Synthetic Panel Data. The Journal of Development Studies, 1-21. https://doi.org/ 10.1080/00220388.2017.1417585

Dang, H.-A., Lanjouw, P., Luoto, J., \& McKenzie, D. (2014). Using repeated cross-sections to explore movements into and out of poverty. Journal of Development Economics, 107, 112-128. https://doi.org/10.1016/j.jdeveco.2013.10.008

Dayioglu, M., \& Demir Seker, S. (2016). Social Policy and the Dynamics of Early Childhood Poverty in Turkey. Journal of Human Development and Capabilities, 17(4), 540-557. https://doi.org/10.1080/19452829.2016.1225700
Deaton, A. (1985). Panel data from time series of cross-sections. Journal of Econometrics, 30(1-2), 109-126. https:// doi.org/10.1016/0304-4076(85)90134-4

Foster, J., Greer, J., \& Thorbecke, E. (1984). A Class of Decomposable Poverty Measures. Econometrica, 52(3), 761-766. https://doi.org/10.2307/1913475

Gibson, J. (2001). Measuring chronic poverty without a panel. Journal of Development Economics, 65(2), 243-266. https:// doi.org/10.1016/S0304-3878(01)00136-5

Herault, N., \& Jenkins, S. P. (2018). How Valid are Synthetic Panel Estimates of Poverty Dynamics? (Society for the Study of Economic Inequality Working Paper Series No. 465). Retrieved from https://ideas.repec.org/p/inq/inqwps/ ecineq2018-465.html

McKenzie, D. (2019). Using Repeated Cross-Sections to Explore Movements into and out of Poverty. Retrieved March 19, 2019, from http://siteresources.worldbank.org/DEC/ Resources/McKenzie_ReplicationFilesforMobility.zip

Seker, S. D., \& Dayioglu, M. (2015). Poverty Dynamics in Turkey. Review of Income and Wealth, 61(3), 477-493. https://doi. org/10.1111/roiw.12112

Sigeze, C., \& Sengul, S. (2018). Türkiye'de Yoksulluğun Rassal Etkiler Multinomial Logit Model ile İncelenmesi. Dokuz Eylül Üniversitesi Sosyal Bilimler Enstitüsü Dergisi, 20(4), 503-521. https://doi.org/10.16953/deusosbil.413034

UN. (2019). Millennium Development Goals - Goal 1: Eradicate Extreme Poverty \& Hunger. Retrieved April 6, 2019, from https://www.un.org/millenniumgoals/poverty.shtml

Urzainqui, D. G. (2017). Poverty Transitions Without Panel Data? An Appraisal of Synthetic Panel Methods. In Seventh Meeting of the Society for the Study of Economic Inequality (ECINEQ). Retrieved from http://www.ecineq. org/ecineq_nyc17/FILESx2017/CR2/p447.pdf

Verbeek, M. (2008). Pseudo-Panels and Repeated Cross-Sections. In L. Matyas \& P. Sevestre (Eds.), The Econometrics of Panel Data: Fundamentals and Recent Developments in Theory and Practice (3rd ed., pp. 369-383). Berlin, Heidelberg: Springer Berlin Heidelberg. https://doi.org/10.1007/9783-540-75892-1_11

World Bank (2021). Poverty headcount ratio at $\$ 1.90$ a day (2011 PPP) (\% of population) - Turkey. Retrieved January 31, 2021, from https://data.worldbank.org/indicator/ SI.POV.DDAY?locations $=$ TR

Wuripe, A. (2018). Dynamics of Government's Role in Poverty Eradication in Turkey: A Study of the Literature. Çukurova Üniversitesi IiBF Dergisi, 22(2), 169-193. Retrieved from http://dergipark.gov.tr/cuiibfd/issue/42702/462759

Yaqub, S. (2000). Poverty Dynamics in Developing Countries (Development Bibliography No. 16). Retrieved from http:// www.ophi.org.uk/wp-content/uploads/ssYaqub-2000.pdf 